\title{
The Role of Atherosclerosis and Inflammation in the Development of Descending Aortic Aneurysms: Special Aspects of Medical Correction
}

\author{
Vladimir Petrovich Krylov', Nikolay Andreevich Manak ${ }^{1}$, Leonid Petrovich Titov ${ }^{2}$, \\ Valentina Nikolaevna Gayduk ${ }^{1}$, Leonid Ivanovich Reut ${ }^{1}$, Nadezhda Vladimirovna Mankevich ${ }^{1}$, \\ Alexander Stanislavovich Zhigalcovitch', Aleksey Leonidovich Smolyakou, \\ Gennady Adolfovich Popel ${ }^{3}$, Roman Nikolaevich Pyzhyk ${ }^{1}$ \\ ${ }^{1}$ Republican Scientific and Practical Centre "Cardiology”, Ministry of Health of Belarus, Minsk, Belarus \\ ${ }^{2}$ Republican Scientific and Practical Centre "Epidemiology and Microbiology”, Ministry of Health of Belarus, Minsk, Belarus \\ ${ }^{3}$ Belarusian Medical Academy of Post-Graduate Education, Minsk, Belarus \\ Email: krylov_v_p@mail.ru
}

How to cite this paper: Krylov, V.P., Manak, N.A., Titov, L.P., Gayduk, V.N., Reut, L.I., Mankevich, N.V., Zhigalcovitch, A.S., Smolyakou, A.L., Popel, G.A. and Pyzhyk, R.N. (2016) The Role of Atherosclerosis and Inflammation in the Development of Descending Aortic Aneurysms: Special Aspects of Medical Correction. Health, 8, 13351348.

http://dx.doi.org/10.4236/health.2016.813134

Received: August 11, 2016

Accepted: October 14, 2016

Published: October 17, 2016

Copyright $\odot 2016$ by authors and Scientific Research Publishing Inc. This work is licensed under the Creative Commons Attribution International License (CC BY 4.0).

http://creativecommons.org/licenses/by/4.0/

(c) (i) Open Access

\section{Abstract}

Modern medicine has achieved much progress in the field of medical and surgical repair of a variety of disorders. It is especially true for the early stages of treatments. In long-term period, however, instead of recovery, we frequently observe progressive regression, which completely annuls all our efforts. Moreover, the algorithm used to correct acute process may sometimes be detrimental to organs and tissues. Such situation is also frequent in the treatment of atherosclerotic descending aortic aneurysms (DAA). This is because the successful medical and even surgical repair to prevent aneurysm rupture in long-term period may trigger some detrimental processes in other regions thus producing negative results of the treatment. The present article doesn't aim to prove some provisions in DAA clinical picture, atherosclerosis and inflammatory states. But we have faced some systematicity at these clinical implications which are absolutely not specified in literature. We have managed to find an explanation for this thing making a scrupulous analysis of nonsurgical sources. Comparing them with our observations, we have found out that aseptic and septic inflammation of connective tissue, probably, is a key component in the formation of DAA disregarding of which correction of dyslipidemia may lead to negative results. We are looking for in-depth research and discussion.

\section{Keywords}

Aneurism Formation, Atherosclerosis and Inflammation, Aortic Aneurisms 


\section{Introduction}

The main reason for aneurism formation is the development and maintenance of chronic recurrent localized inflammation induced by various contagious matters and vascular wall infiltration with cells of the immune system, and production of pro-inflammatory factors including cytokines and metalloproteinases, which contribute to the development of atherosclerosis and aneurysms [1].

Natural history of DAA is not fully detailed. A traditional view implies that the progression of DAA diameter with subsequent rupture is inevitable, especially if the dilatation rate is $0.5 \mathrm{~cm}$ at 0.5 years, or if a patient smokes and has high BP, although some patients may show stabilization of the disease [2] [3].

For years, degenerative atherosclerotic changes in aortic wall have been blamed for the development of aneurysm of descending aorta. At the same time, some authors [4]-[7] underline a number of significant differences between atherosclerosis and aneurysm. Thus, atherosclerosis is primarily localized in the intima and is productive due to accumulated atherosclerotic plaques, which contributes to the development of aortoiliac occlusive disease (Leriche's syndrome). As for DAA, the process is characterized by inflammatory changes occurring in aortic tunica media and tunica externa secondary to medial degeneration, reduced elastic structures and altered collagen production. It probably suggests that pathogenetic components of DAA and atherosclerosis are different although these diseases are often coexistent. Some points are currently available concerning dysgenics of both ascending aorta, and in the settings of DAA [8] [9]. The clue might be undifferentiated forms of dysplasia of connective tissue.

In fact, the integrity of any structure of human body is determined by the fame (carcass) function of connective tissue. It shapes morphological and functional integrity of human body. Thus, the components of tunica media of aorta include elastic membranes, smooth muscle cells, fibroblasts and individual elastic fibers whereas those of tunica externa include loose connective tissue comprising collagen and elastin fibers.

Tsaregorodtsev A. G. [10] performed autopsies of young patients with signs of connective tissue dysplasia (CTD) and found the loss of connective tissue and elastic structures of the aorta with mucoid matter substituted in aneurysms of descending thoracic aorta. This congenital defect of muscle component, internal elastic lamina and collagen fibers contributes to the impaired structure and jeopardizes vascular wall making a resistive arterial vessel capacitive.

Gens A. P. et al. [11] have found the thinning of media, low elastic membrane volume fraction, fragmentation and cystic degeneration present in tunica media of aorta in the aneurysm of ascending and thoracic-abdominal aorta. In more than $50 \%$ of individuals over 40 , those changes were coupled with atherosclerotic plaques presented as atheromas and calcifications.

Some authors emphasize the role of inflammation and apoptosis of smooth muscle cells, which contributes to the pathogenesis of aneurysm. Therefore, angiotensin II stimulates the production of cyclophilin A by smooth muscle cells through the induction of oxidative stress which in turn produces haemostatic effect on regulation of mono- 
cytes, dendrite cells, neutrophils, eosinophils, T-lymphocytes and macrophages to this region triggering inflammatory cascade resulting in the disintegration of aortic wall [12] [13]. Pro-inflammatory effect produced by AT II involves the activation of cytokines including tumor necrosis factor alpha (TNF- $\alpha$ ) and interleukins which in turn enhance production of C-reactive protein (CRP) further exacerbating vascular inflammation and endothelial dysfunction [14]-[16]. Thin and fragmented elastin, enhanced collagen production in the arterial wall, thick intima and stiffer arteries [17] become visible. As a result, pulse wave propagation is changed with an earlier return of the reflected wave [18].

Multifactorial development of DAA was an incentive for us [19] [20] to formulate pathogenetically substantiated and standardized regimen for management using widely accepted medical products with two or three targets, and with operative treatment if there was a risk of rupture. This modality has been known as "sparing" treatment. Subsequently, we assessed 2-year follow-up data of 121 individuals and 4-year data of 99 individuals using statistical software. We obtained evidence that inflammatory processes (with CRP as a marker), high BP, lack of compliance and severe dyslipidemia (presented as high values of LDLPS and atherogenic index (AI)) were the main cause of DAA evolution. Aneurysm length and diameter did not reflect mechanisms responsible for DAA progression and were a criterion for the severity of late changes which required more focus on the treatment and follow-up.

Thus, at 4 years, no negative changes in aneurysm dimensions in patients with CRP < $2.7 \mathrm{mg} / \mathrm{l}$; LDLPS < $2.7 \mathrm{mmol} / \mathrm{l} ; \mathrm{AI}<2.68$ and $\mathrm{BP}<132.4178 .6 \mathrm{~mm} \mathrm{Hg}$ were registered. This group was referred to as the "Group of the favorable course". In subjects who had negative changes in aneurysm dimensions (more than $5 \mathrm{~mm}$ within 6 months), the estimates were as follows: CRP > $8.3 \mathrm{mg} / \mathrm{l}$; LDLPS $>3.46 \mathrm{mmol} / \mathrm{l}$; $\mathrm{AI}>4.05$ and $\mathrm{BP}>$ $142.1 / 86.77 \mathrm{~mm} \mathrm{Hg}$, with aneurysm diameter at baseline $>44.3 \mathrm{~mm}$. Those patients were referred to the "Group of adverse course" and they received differentiated medical treatment with mandatory monitoring of those estimates every 3 to 6 months. Treatment regimen was relatively standardized and included exercise limitation, cardiomagnyl administration or other ASA drugs at a dose of $75 \mathrm{mg}$ after daytime or evening meal daily; CRP examination performed every 3 to 6 months and azithromycin (sumamed or doxycyclin) administration if CRP values were $>3 \mathrm{mg} / \mathrm{L}$; persistent antihypertensive therapy with target value of $\mathrm{BP}<135 / 85 \mathrm{~mm} \mathrm{Hg}$ with beta-blockers, amlodipine and ACE-inhibitors as preferable treatment; normalization of dyslipidemia with mandatory control every 3 months. Statin therapy was mandatory as it strengthened the aortic wall and blocked inflammation.

If this regimen is not fully effective (estimates of favorable course are not attained or baseline values of DAA adverse course are deteriorated), the indications for surgical treatment are established. Subjects with favorable course received selective post-symptomatic treatment with mandatory control within 6 - 18 months.

The aim of the study was to assess a probable multifactorial variability of DAA development to search for an optimal modality for correction. 


\section{Materials and Methods}

\section{Patient characteristics}

A total of 273 patients with DAA received treatment in clinical settings of the Republican Research and Practical centre "Cardiology" in the course of six years. During this period, three groups of patients were produced for a statistical analysis: 121 patients with a 2-year follow-up period, 99 with a 4 -year follow-up period, and 97 patients with a 5-year follow-up period.

The DAA groups examined were not statistically different by age, sex, and aneurysm size including those above or below $50 \mathrm{~mm}$, magnitude, and thoracic and abdominal aneurysm diameter. Statistical data were not affected by a reduced number of patients over a 5-year period.

Among those with the 5-year follow-up period, 24.7\% received surgical treatment. Sixteen subjects received aortic prostheses and 8 subjects were implanted with a stentgraft. Over the last year, there were no surgical interventions performed. All individuals received permanent medical treatment in line with their estimates of favorable and adverse course.

Seventy-three subjects (75.3\%) received no surgery. Most of them were patients who had relatively minor aneurysms, and older patients with large aneurysms and present co-morbidities. The latter had absolute contraindications for operative treatment.

\section{Methods}

1. Clinical investigations, including CT-angiography, aortic angiography, coronary angiography, and US imaging.

2. Surgical treatment: aortic iliofemoral bifurcation prosthesis and endovascular stent-graft implantation.

3. Medical therapy to strengthen the aortic wall including constantly administered combination of ACE-inhibitors with amlodipine; beta-blockers, and statins and courses of macrolid antibiotics (roxithromycin, azithromycin) if there are signs of inflammation (evidenced by CRP data), and symptomatic therapy. The values of CRP were defined in venous blood specimens represented by $\mathrm{mg} / \mathrm{L}$ using latex turbidimetric immunoassay by Cobas JNTEGRA 400 analyzer and Roche Diagnostics (Switzerland) system.

4. The data statistical processing was made using Statistica 5.5 StatSoft Corp (USA) software for medical and biological testing. The estimates of investigated factors are represented as mean $(\mathrm{M})$ and mean error $(\mathrm{m})$. To define statistical significance between estimates of interest, Student t- test was used. Difference was considered to be statistically significant if $\mathrm{P}$ was $<0.05$.

\section{Results}

As mentioned above, Groups of patients with 2-, 4- and 5-year follow-up period were not different by age, sex, aortic disorder type and size, although the number of subjects with large aneurysms was somewhat increased [21]. The results of the suggested modality (sparing treatment) of patients with DAA have confirmed to improvement of sur- 
vival rates and cost-effectiveness. As for the aneurysm rupture, it was not the main cause of death.

One insoluble question, however, remained as to why among 97 patients there had been no ruptures over a 5-year period and no indications for surgery, although mortality rates due to other co-morbidities increased. The dynamics of the mortality due to aneurysm rupture and co-morbidity at 2, 4 and 5 years of sparing treatment is shown in Table 1.

Data analysis and the comparison against various published investigations related to this disorder allowed for a more in-depth understanding of DAA development.

\section{Discussion}

The starting point was the assumption that there existed a potential correlation between a wide variety of factors triggering the development of DAA and the co-morbidity as the medical treatment either component of this cluster seems to change the processes observed in some other pathogenetically adjoined region.

With no capacity to independently investigate the issue of DAA development and assess dynamics changes during the treatment, we tried to classify data that have been published related to the issue to confirm or deny discussions concerning the findings obtained. We have posed questions:

- What is the main predisposing factor of the development and progression of DAA?

- Why the medically reduced risk of aneurysm rupture may lead to an increased co-morbidity and mortality rate associated with that?

First, let us speak about atherosclerosis and inflammation. This issue has been covered extensively in literature and we will mention parts that are entirely consistent to our inquiry.

Inflammatory, traumatic, chemical or other injuries of human loose connective tissue (fibroblasts, macrophagocytes, tissue basophils, plasmatic, adipose and pigment cells) increase interleukin production. It is the key inducer of acute phase protein synthesis by liver (CRP, serum amyloid A and fibrinogen) [22]-[24], and when the production of this anti-inflammatory cytokine becomes increased, it produces a pro-inflammatory effect on tissues due to autoimmune reaction. From this moment on, the inflammation is no more local but rather generalized [25].

Acute phase proteins, coupled with LDLPS, fail to insert in cells, as they are perceived as alien. As a result, those endogenous protein macromolecules that underwent

Table 1 . The dynamics of the mortality due to aneurysm rupture and co-morbidity at 2,4 and 5 years of sparing treatment.

\begin{tabular}{cccc}
\hline Follow-up period & No. of patients & $\begin{array}{c}\text { Mortality rate due to } \\
\text { aneurysm rupture }\end{array}$ & $\begin{array}{c}\text { Mortality rate due to } \\
\text { co-morbidity }\end{array}$ \\
\hline 2 years & 121 & $3.3 \%$ & $7.4 \%$ \\
4 years & 99 & $8.1 \%$ & $13.1 \%$ \\
5 years & 97 & $8.25 \%$ & $20.6 \%$ \\
\hline
\end{tabular}


denaturation (peroxidation, glycation and immune complex generation) get absorbed by blood and tissue monocytes and macrophages (functional phagocytes) and adhere to vascular endothelial surface [26]. As for the infectious injury of loose connective tissue, neutrophils as well as functional phagocytes, absorb and deactivate intrusive bacteria. It suggests that the inflammatory syndrome and atherogenic processes are presented with the same functional responses [24].

Thus, the development of atherosclerosis includes the following trigger and specificity:

1. Endogenous malformation, i.e. blockage of cell receptor absorbance of LDLPS, which results in a subsequent deficiency in key essential polyunsaturated fatty acids.

2. Blood LDLPS deposit with subsequent adhesion to arterial intimal acute phase proteins.

Therefore, two problems emerge when cell receptor absorbance of LDLPS is blocked, and each of those involves global challenges, so the questions are:

1. What should each cell do to survive in the presence of scarce essential polyunsaturated fatty acids that help to preserve functional capacities?

2. How to eliminate LDLPS (the key transporter of essential polyunsaturated fatty acids) which couple with acute phase proteins and therefore become alien?

Non-treatment of those two conditions contributes to the development of atherosclerosis and some cascade local and generalized disorders.

The issue is more exacerbated because in the settings of scarce essential polyunsaturated fatty acids, the cell starts adaptation and initiates eukozanoid synthesis (C 20 polyunsaturated fatty acids) instead of omega- 6 arachidonic fatty acid (C 20:4) and omega-3 eicosapentanoic fatty acid (C 22:5) [27]. Thus, in the settings of adaptation, the cells activate endogenous trienoic fatty acid [28] in membranous phospholipids instead of exogenous penta- and tetraenoic essential acid. It disturbs physical and chemical features of cell membranous matrix (lipid bilayers) and is detrimental to the function of all proteins of the membrane and the function of highly differentiated cells.

When omega- 6 tetra to omega-3 penta and hexanoic essential polyunsaturated fatty acids and their adaptation to those changes are deficient, they in situ synthesize omega-9 polyunsaturated fatty acids and form leukotrienes producing a prominent pro-inflammatory effect [29]. Thereby, the potential of the inflammatory syndrome in atherosclerosis becomes much more noticeable compared to inflammations of other origin.

Additionally, cell synthesis of prostaglandins (prostacyclin) and thromboxanes derived from omega- 9 fatty acids, and the prevalence of omega- 9 fatty acids in cell membranous phospholipids contributes to a specific clinical impairment of metabolic regulation, primarily, of carbohydrates and ion composition of intracellular medium.

The functional entity of inflammatory response and atherosclerotic syndrome suggests that the lipid infiltration (impaired transport of polyunsaturated fatty acids) may be preceded or followed by the inflammation [30].

As cardiovascular diseases are multifactorial in nature, and tightly associated with other potent factors, it seems appropriate to consider their synergetic effect produced 
on human health. Our long-term observations of patients with DAA using a currently accepted concept of cumulative cardiovascular risk [31]-[33] armed us with a morein-depth understanding that this disorder involves integrated lesions. But in this case, atherosclerosis might play an inferior role [24] [34]-[36]. It gave us grounds to search for a cumulative pathogenetic component of this disorder to further correct the treatment modality.

The clinical and histological comparisons have shown that during aortic prosthesis due to DAA, the overwhelming majority of proximal and distal anastomoses are applied in the area of advancing (or actual) wall disruption (including cell components and intimal, medial and adventitial fibers). The margins of altered tissue are not always visible during the operation or visually underestimated against adjoined areas. In case of 'sheer' aortic atherosclerosis, the margins of healthy tissues are more prominent, and the histological picture is well assessed.

Therefore, it turned out to be impossible to explain "vague" visual and histological picture of DAA solely by atherosclerosis. Such fragmentation of cell and tissue components of aorta seems to stay beyond inflammation and connective tissue dysfunction. It suggests that there might be some combination lesions involved with the irregular connective tissue complicated by the inflammation, atherosclerosis and arterial hypertension. Moreover, the detectability of phenotypic signs of connective tissue dysplasia among DAA patients is much better compared to subjects with common atherosclerosis.

A wide number of literature sources are available related to connective tissue disorders including those of descending aorta [35]-[37]. Connective tissue makes up almost $50 \%$ of human body mass and represents a complex basal, structural and multifaceted system which combines a vast number of organs and tissues. It is independent but interferes into other tissues [38]-[40].

Connective tissue disease is sometimes poorly or underdiagnosed. Predisposing factors, such as physical exercise, psychoemotional stress, infection, intoxication, injuries, pain, etc., provide conditions for severe complications [41]. Morphological investigations in young subjects with connective tissue showed adventitial collagen fiber deformation, loose and fragmented elastic fibers, reduced smooth muscle cells and collagen-poor medial disintegration, and highly visible crumbly endothelial layer [42].

It is known that the more severely affected the vascular wall is, the quicker is the development of atherosclerosis, arterial hypertension and other conditions. Arterial well-being depends primarily on the feature of endothelium. It coordinates almost all processes taken place in them. Some authors [36] [43]-[45] state that the endothelium plays a key role in the development of atherosclerosis, hypertension, strokes, infarctions, chronic renal failure, various metabolic abnormalities and other disorders. Being the barrier between blood and vessels, it plays a role of "giant organ" penetrating into all tissues with a number of significant functions.

Nitric oxide (NO) plays is crucial for supporting the endothelial function providing vasodilation, reducing common peripheral vascular resistance, preserving arterial elas- 
ticity, and hampering platelet adhesion and monocyte migration [43] [46]. It produces antiatherogenic, inti-inflammatory and antioxidant effects [26] [47].

Changes in smooth muscle cell tone are directly proportional to vascular wall stiffness. Smooth muscle cell tone is regulated systematically by neurohumoral mechanisms (via autonomic nervous, renin-angiotensin-aldosterone and kallikrein-kinin system), and locally via endothelial cells, i.e prostaglandins, nitric oxide, endothelia, etc. Therefore, the controlling role of endothelium in respect of arterial stiffness is undeniable [48] [49].

Arterial bed stiffness determined by abnormal collagen, elastin and various components of the basic matter represents an integrated index of structural components of vascular wall, blood pressure and control mechanisms and an independent precursor of poor outcome [44] [49].

Arterial wall may be affected by genetic (dysmorphology and abnormal proportion of structural components) and indirect factors (age, blood pressure, cholesterol index, glucose profile and other risks) which may improve arterial stiffness [34] [43] [49]. Thus, we observe a multifactorial nature of visceral injuries occurring in the presence of connective tissue dysfunction, which may reduce 2 times a life expectancy in individuals with cardiovascular diseases [24].

Thus, we have: all-cause injuries of loose connective tissue induce acute phase proteins in blood and tissues which coupling with LDLPS prevent them from inserting into cells depriving them of their power potential. The resultant endogenous protein macromolecules (acute phase proteins + LDLPS) are absorbed in blood and tissues by monocytes/macrophages and adhere to vascular endothelial surface. Atherosclerosis has now developed.

If essential polyunsaturated fatty acids are lacking, the cell induces its adaptation mechanisms. It compromises physical and chemical properties of cell membranous matrix, and modulate functioning of all in-built proteins and highly differential cells. As a result, clinical signs of impaired metabolic regulation emerge (it primarily concerns carbohydrates and intracellular ion composition). Moreover, the resultant leukotrienes produce pro-inflammatory effects.

Consequently, the development of DAA per se necessitates global enhancement of tissue and pro-inflammatory processes and contributes to the development of new sites.

As the whole process is associated mainly with the connective tissue, it is to be assumed that clinical manifestation of DAA in basal dysfunction may be quite different depending on the severity. Note, that the rapid development of endothelial dysfunction and arterial stiffness associated with connective tissue dysplasia (CTD) adversely affect the course and prognosis.

Therefore, the absence of any prevailing manifestations in the DAA course together with mortality data (Table 1) suggest that the disease includes a wide number of 'peer' pathological mechanisms any of which at any point may prove fatal. Thus, DAA is considered to be an individual marker of multifaceted lesion of organs and tissues, which is most probably develop based on some preexisting dysfunction (dysplasia) of connective 
tissue.

This concept might explain a wide range of DAA fatal outcomes due to other cardiac and vascular conditions, diabetes mellitus, and polyorgan failure, among which aneurysm rupture is not a principal factor. For that reason, operative treatment is neither a prevention from aneurysm rupture, nor it improves death rates [24] [50]. Data obtained from EVAR [51] [52] multicentre investigation are consistent with those findings.

\section{Conclusions}

Comparisons of published data and our own findings suggest that atherosclerosis is not always the key factor of DAA as the manifestation of that is associated with multiplestage abnormalities taken place in connective tissue resultant from the sites of acute and chronic infections in human system or mechanistic, chemical or other factors affecting loose connective tissue. Rheumatism and systemic lupus erythematosis [53], or the given disorder within the arterial wall (known as Takayasu's disease) may serve as an example for that [54]. The development of DAA results a great deal of forms by the connective tissue disease due to its polyorgan damage.

Atherosclerosis is disfavored by such an "aggressive" behavior of acute-phase proteins, which hampers normal absorption of LDLPs and VLDLPs by cells. The resultant hyperlipoproteinemia suggests that the impaired cellular absorption of saturated fatty acids (SAFAs) and essential polyunsaturated fatty acids is independent on the origin and characteristic of the acute phase of the inflammation rather than atherosclerosis.

The issue of hyperlipoproteinemia and inflammation represents a challenge in establishing treatment regiment in individual patients. Based on the data obtained from our investigations, LDLPS $>3.46 \mathrm{mmol} / \mathrm{l}$ was a marker of a high-risk course of DAA, with the level of the favorable course being $<2.7 \mathrm{mmol} / \mathrm{l}$. We therefore try to reduce LDLPs values in our patients to the level of the favorable course. Due to this practice, we managed to completely avoid cases of aneurysm rupture over a 5-year follow-up period (Table 1), but failed to reduce mortality rates in the presence of co-morbidity. Despite all our efforts, it tended to be fatal.

However, if to consider the issue from the etiopathgenetic point of view, it becomes clear that when LDLP levels become acutely reduced resulting from the deficiency in polysaturated fatty acids, the situation becomes worse. The thing is that the cells as part of the adaptation process include only endogenous trienoic acid in membraneous phospholipids instead of exogenous penta- and tetra-enoic essential fatty acids yet enhancing pro-inflammatory effects.

Consequently, reduced LDLPs and VLDLPs enforce a deficiency in cellular essential polyunsaturated fatty acids, potentiating the impairment of physical and chemical features of matrix (lipid bilayers) of the cell membrane compromising the function of the in-built proteins, and highly differentiated cells, i.e. the existing metabolic regulatory global tissue and organ dysfunction in DAA which potentiates the pathological manifestation of "sleeping" lesions of the dysfunction. Thus, we stimulate co-morbid condi- 
tions.

The correlations contributing to the development of DAA mentioned above do not allow assessing the existing hyperlipoproteinemia only by pathological processes contributing to atherosclerosis progression as the presence of inflammation leads inevitably to a lack of cellular polyunsaturated fatty acids which might be balanced by either inflammation suppression, or increased LDLPs and VLDLPs estimates. Therefore, it seems unfeasible to administer statin therapy without establishing the probable presence of inflammation. If the therapy is to be administered, the addition of antibiotics is appropriate.

A wide range of etiologic factors triggering universal pathogenetic mechanisms of the disease afford considering atherosclerosis and inflammation not as a clinical entity, but as a syndromes [24]. From our perspective, the associations between these syndromes provide various clinical manifestations of the diseases.

DAA is one of them. Its origins may involve the congenital or acquired structural condition of connective tissues. Anyway, the whole chain of the development of the atherosclerosis and inflammation syndrome begins from the loose connective tissue. It appears unimportant whether the onset was septic or aseptic, the most important is that the mechanism has been launched and it all depends on the co-morbidity, microbial, viral, fungal lesions, and features of autoimmune responses.

It is noteworthy that the block of interleukin production is to be the key aim of the treatment. Sanitation of possible infection, co-morbidity management, and a search of additional predictors of inflammation and their treatment are of prime importance. Zero level of CRP (for acute-phase inflammation) might be considered in clinical practice as a normal range because if it is positive, the block of cellular polyunsaturated fatty acid transport is ongoing.

During the treatment, it is sometimes assumed that uric acid may increase CRP. It is unlikely and requires a separate study. It is reasonable to assume that the mechanism of inflammation involves some kind of autoimmune response with the manifestation of this disorder. It should be remembered, however, that the uric acid synthesis, despite any links to DAA, represents another disorder, and the increased CRP should be normalized to reduce the block of cellular polyunsaturated fatty acid transport.

Thus, it seems evident that the underlying mechanisms of vascular aneurysm development involve connective tissue dysfunction. The wide range of forms, sites and clinical manifestations is largely dependent on the dysfunctional (dysplasia) severity of the connective tissue, patient's age, elasticity, endothelium, and arterial stiffness, which determine the features of hydro-and hemodynamics [55].

In young patients, severe connective tissue disease is manifested by common aortic and vascular aneurysms. At an advanced age, when multiple co-morbidities are accumulated (partly due to the dysfunction), the injury (both septic and aseptic) of loose connective tissue together with inflammation and (or) atherosclerosis syndrome emerge; with autoimmune response at an early stage, and DAA development at a later stage. 
Everything mentioned above is our assumptions but it is a good incentive to further search for answers to our questions. We suggest a concept of a global bank of histological findings of patients with aortic aneurisms. This is the only way to understand more deeply the intricacies of pathological processes involved.

\section{References}

[1] Tsao, P. and Burasor, I. (2011) The Need for Novel Biomarkers of Abdominal Aortic Aneurysm Disease. Scientific Journal of the Faculty of Medicine in Nis, 28, 119-124.

[2] Eberhardt, R.T. and Coffman, J.D. (2004) Cardiovascular Morbidity and Mortality in Peripheral Arterial Disease. Current Drug Targets. Cardiovascular \& Hematological Disorders, 4, 209-217.

[3] Aggarwal, A., Qamar, V. and Sharma, A. (2011) Abdominal Aortic Aneurysm: A Comprehensive Review. Experimental \& Clinical Cardiology, 16, 11-15.

[4] Juraszek, A., Bayer, G., Dziodzio, T., Kral, A., Laufer, G. and Ehrlich, M. (2013) Evaluation of the Intraoperative Specimens of the Thoracic and Abdominal Aorta. Journal of Cardiothoracic Surgery, 8, 110. http://dx.doi.org/10.1186/1749-8090-8-110

[5] Fishbein, G.A. and Fishbein, M.C. (2009) Arteriosclerosis: Rethinking the Current Classification. Archives of Pathology \& Laboratory Medicine, 133, 1309-1316.

[6] Novikova, E.G., Titova, G.P. and Galankina, I.E. (2013) Morphological Changes in Aortic Wall in Dissecting Aneurysm. Arkhiv Patologii, 6, 3-8.

[7] Novikova, E.G. and Galankina, I.E. (2012) Anatomico-Pathological Criteria of Dissecting Aortic Aneurysm. Arkhiv Patologii, 5, 12-17.

[8] Nikonenko, A.A. and Trilin, A.V. (2013) The Role of Cyclosporine A in Pathogenesis of Abdominal Aortic Aneurysm. Cardiologia i Serdechnososudistaya Khirurgiya, 6, 39-42.

[9] Kemma, A., John, Thomas, L.F. and Serrius Patrick, V. (2011) Cardiovascular Disease Edition. "ESC Guidelines" GEOTAR-Media, 1209-1248. (In Russian)

[10] Tsaregorodtsev, A.G. (2009) Dysplasia of Connective Tissue: Vascular Impairments. Causes for Sudden Death. Sibirsk Medical Journal, 1, 34-39.

[11] Gens, A.P. (2004) Surgical Treatment of Aortic Aneurysm due to Connective Tissue Dysplasia. RAMN, Russian Research Centre of Surgery, Moscow, 37.

[12] Leiva, M.S. and Fish, S.A. (1992) Leucocyte Chemoatractive Activity of Cyclophilin. Journal of Biological Chemistry, 267, 1168-1171.

[13] Neal, L. (2009) Weintraub Understanding Abdominal Aortic Aneurysm. The New England Journal of Medicine, 10, 11.

[14] Capri, M., Salvioli, S., Sevini, F., et al. (2006) The Genetics of Humanlongevity. Annals of the New York Academy of Sciences, 1067, 252-263. http://dx.doi.org/10.1196/annals.1354.033

[15] Wang, M., Zhang, J., Spinetti, G., et al. (2005) Angiotensin 11 Activates Matrix Metalloproteinase Type 11 and Mimics Age-Associated Carotid Arterial Remodeling in Young Rats. American Journal of Pathology, 167, 1429-1442. http://dx.doi.org/10.1016/S0002-9440(10)61229-1

[16] Venugopal, S.K., Devaraj, S., Yuhanna, I., Shaul, P. and Jialal, I. (2002) Demonstration That C-Reactiive Protein Decreases eNOS Expression and Bioactivity in Human Aortic Endothelial Cells. Circulation, 106, 1439-1441. http://dx.doi.org/10.1161/01.CIR.0000033116.22237.F9 
[17] Wang, M., Zhang, J., Jiang, L.Q., et al. (2007) Proinflammatory Profile within the Grosly Normal Aged Human Aortic Wall. Hypertension, 50, 219-227. http://dx.doi.org/10.1161/HYPERTENSIONAHA.107.089409

[18] Lim, M.A. (2009) Arterial Compliance in the Elderly: Its Effect on Blood Pressure Measurement and Cardiovascular Outcomes. Clinics in Geriatric Medicine, 25, 191-205. http://dx.doi.org/10.1016/j.cger.2009.01.001

[19] Gayduk, V.N., Krylov, V.P., Reut, L.I., Smolyakov, A.L. and Mankevich, N.V. (2014) Management Optimization for Patients with Chronic Atherosclerotic Aneurysm of Descending Aorta. Meditsina, 3, 20-26.

[20] Mankevich, N.V., Mrochek, A.G., Krylov, V.P., Gayduk, V.N., Reut, L.I. and Smolyakov, A.L. (2015) Predictors of the Progression of Atherosclerotic Aneurysms of Descending Aorta and Repair. Kardiologiya $v$ Belarusi, 5, 63-73.

[21] Krylov, V.P., Mrochek, A.G., Gaiduk, V.N., Reut, L.I., Smaliakou, A.L., Mankevich, N.V. and Pizhik, R.N. (2016) A Five-Year Experience of Sparing Treatment of Descending Aortic Atherosclerotic Aneurysms. World Journal of Cardiovascular Surgery, 6, 47-54. http://dx.doi.org/10.4236/wjcs.2016.64009

[22] Patel, P., Carington, D., Strachan, D.P., Leatham, E., Goggin, P., Nitrfield, T.C. and Mendall, M.A. (1994) Fibrinogen: A Link between Chronic Infection and Coronary Heart Disease. Lancet, 343, 1634-1635. http://dx.doi.org/10.1016/S0140-6736(94)93084-8

[23] Titov, V.N. (1998) Patherosclerosis Pathogenesis for 21th Century. Clinical Laboratory Diagnosis, 3-11.

[24] Titov, V.N. (1999) The Relationship between Atherosclerosis and Inflammation: Specificity of Atherosclerosis as an Inflammatory Process. Rossiyskiy kardiologicheski zhurnal, 5, 1-15.

[25] Steel, D.M. and Wikithead, A.S. (1991) The Major Acute Phase Reactants C-Reactive Protein, Serum Amyloid F Component and Serum Amyloid A Protein. Immunology Today, 15, 81-88. http://dx.doi.org/10.1016/0167-5699(94)90138-4

[26] Berliner, J.A., Navab, M., Fogelman, A.M., Frank, J.S., Demer, L.L., Edwards, P.A., Watson, A.D. and Lusis, A.J. (1995) Atherosclerosis: Basic Mechanism Oxidation, Inflammation, and Genetic. Circulation, 91, 2488-2496. http://dx.doi.org/10.1161/01.CIR.91.9.2488

[27] Jialall, D.R. (1996) Low Density Lipoprotein Oxidation? Antioxidants and Atherosclerosis: A Clinical Biochemical Perspective. Clinical Chemistry, 42, 498-506.

[28] Johnson, P.V. (1985) Dietary Fat, Eicosanoids and Immunity. Advances in Lipid Research, 4, 103-141. http://dx.doi.org/10.1016/B978-0-12-024921-3.50010-1

[29] Schmidt, M.L.H., Ford-Hunchinen, A.W. and Bray, M.A. (1980) Leucotriene B: A Potential Mediator of the Inflammation. Journal of Pharmacy and Pharmacology, 32, 517-518. http://dx.doi.org/10.1111/j.2042-7158.1980.tb12985.x

[30] Belova, L.A. (1997) Biochemistry of Inflammatory Processes and Vascular Damage. The Role of Neutrophils. Biokhimia, 62, 659-668.

[31] Martinov, A.I., Gudilin, A., Drokina, O.V., Kalinina, I.Y., Nechaeva, G.I. and Tsikunova, Y.S. (2015) Endothelial Dysfunction in Patients with Connective Disuse Dysplasia. Lechaschiy Vrach, 2, 18-21.

[32] Prophylaxis and Control of Noninfectious Diseases and Injuries in the Russian Federation (Project) (2008) Profilaktika zabolevaniy I ukreplenie zdorovya, 9-19.

[33] Kukhartchuk, V.V. (1996) Treatment of Atherosclerosis. Terapevticheskiü Arkhiv, 5-8.

[34] Tvorogova, M.G., Vasin, P.N., Rozhkova, T.A., Kukharchuk, V.V. and Titov, V.N. (1998) Lipid Composition of High-Density Lipoproteins in Inherited Hyperlipoproteinemias. Is- 
sues of Medical Chemistry, 44, 452-459.

[35] Biasi, F., Ranzi, M.L., Erba, M., Tarsia, P., Raccaneli, P., Fagetti, L. and Alegra, L. (1996) No Evidence for the Presence Helicobacter Pylori in Atherosclerotic Plaques in Abdominal Aorta Aneurysm Specimens. Atherosclerosis, 126, 339-340.

[36] Clifton, P.M., Mackinnon, A.M. and Barter, P.J. (1985) Effect of Serum Amyloid A Protein (SAA) on Composition Size and Density of High Density Lipoprotein in Subjects with Myocardial Infarction. Lipid Research, 26, 1389-1398.

[37] Danesh, J., Collins, R. and Peto, R. (1997) Chronic Infection and Coronary Heart Disease. Is there a link? Lancet, 350, 430-436. http://dx.doi.org/10.1016/S0140-6736(97)03079-1

[38] Folsom, A.R., Nieto, J., Sorlie, P., Chambles, E. and Gracham, D.Y. (1998) Helibacteria Pylori Seropositivity and Coronary Heart Disease Incidence. Circulation, 98, 845-850. http://dx.doi.org/10.1161/01.CIR.98.9.845

[39] Fuster, V., Badimon, J.J. and Cjesebro, J.H. (1992) The Pathogenesis of Coronary Artery Disease and the Acute Coronary Syndrome. New England Journal of Medicine, 326, 242 250. http://dx.doi.org/10.1056/NEJM199201233260406

[40] Fyfe, A.I., Rothenberg, L.S., de Beer, F.C., Cantor, R.M. and Ritten, J.I. (1997) Association between Serum Amyloid a Proteins and Coronary Artery Disease. Evidence from Two Distinct Arteriosclerotic Processes. Circulation, 96, 2914-2919.

http://dx.doi.org/10.1161/01.CIR.96.9.2914

[41] Netchaeva, G.I. and Viktoriva, I.A. (2007) Connective Tissue Dysplasia: Terms, Diagnosis, Management. Blankom, Omsk, 188.

[42] Konev, V.P. (2011) Morphological Phenomena for Sectional Diagnosis of Connective Tissue Dysplasia: Review. Sibirsky Meditsinski Zhurnal, 3, 19-22.

[43] Strazhesko, I.D., Akasheva, D.U., Dudinskaya, E.N., Kruglikova, A.S., Tkacheva, V.S. and Pikhtina, V.S. (2013) Renin-Angiotensin-Aldosterone System and Vascular Ageing. Kardiologiya, 7, 78-84.

[44] Osipov, S.G. and Titov V.N. (1982) Immune Complexes and Atherosclerosis. Kardiologiya, 119-125.

[45] Chui, B., Vira, E., Tucker, W. and Fong, I.W. (1997) Chlamidiapneumoniae, Cytomegaloviruses and Herpes Simplex Virus in Atherosclerosis of the Carotid Artery. Circulation, 96, 2144-2148. http://dx.doi.org/10.1161/01.CIR.96.7.2144

[46] Santhanam, L. (2008) Arginase and Vasrular Aging. Journal of Applied Physiology, 105, 1632-1642. http://dx.doi.org/10.1152/japplphysiol.90627.2008

[47] Ryabov, G.A. and Azizov, Y.M. (2001) The Role of Nitric Oxide in the Regulation of Cell Processes in the Development of Polyorgan Failure. Anesteziologiya i Reanimatologiya, 1, 8-13.

[48] Drokina, O.V. (2014) Clinical Significance of the Assessment of Arterial Stiffness and Endothelial Vasomotor Function in the Settings of Connective Tissue Dysplasia. MD Thesis, State Educational Institution of Higher Professional Education, Barnaul, 23.

[49] Polevshikov, A.V., Nazarov, P.G., Kozlov, S.V., Galkina, E.V. and Berestovaya, L.K. (1996) Regulation of Blood Neutrophil Function by Serum Amyolid P and C-Reactive Protein. Sibirsky Meditsinski Zhurnal, 84, 67-72.

[50] Krylov, V.P., Titov, L.P., Gayduk, V.N., Reut, L.I., Smaliakou, A.L. and Mankevich, N.V. (2015) Atherosclerotic Descending Aortic Aneurysm. World Journal of Cardiovascular Surgery, 5, 91-101. http://dx.doi.org/10.4236/wjcs.2015.59015

[51] EVAR Trial Participants (2005) Endovascular Aneurysm Repair versus Open Repair in Pa- 
tients with Abdominal Aortic Aneurysm (EVAR Trial 1): Randomised Controlled Trial. Lancet, 365, 2179-2186. http://dx.doi.org/10.1016/S0140-6736(05)66627-5

[52] EVAR Trial Participants (2005) Endovascular Aneurysm Repair and Outcome in Patients Unfit for Open Repair of Abdominal Aortic Aneurysm (EVAR Trial 2): Randomised Controlled Trial. Lancet, 365, 2187-2192. http://dx.doi.org/10.1016/S0140-6736(05)66628-7

[53] Gu, L., Johnson, M.W. and Lusis, A.J. (1999) Quantitative Trail Locus Analysis of Plasma Lipoprotein Levels in an Autoimmmune Mouse Model. Interaction between Lipoprotein Metabolism, Autoimmune Disease and Atherosclerosis. Arteriosclerosis, Thrombosis, and Vascular Biology, 19, 442-453. http://dx.doi.org/10.1161/01.ATV.19.2.442

[54] Seco, Y., Sato, O., Takagi, A., Tada, Y., Matsuo, H., Yaguta, H., Okumura, M. and Yazaki, Y. (1996) Restricted Usage of T-Cell Receptor V $\alpha$-V $\beta$ Genes in Infiltrating Cells in Aorta Tissue of Patients with Takayasus Arteritis. Circulation, 93, 1788-1790.

http://dx.doi.org/10.1161/01.CIR.93.10.1788

[55] Krylov, V.P., Mrochek A.G., Titov, L.P., Gaiduk, V.N., Reut, L.I. and Smaliakou, A.L. (2014) Can We Change a Look at Atherosclerotic Aortic Aneurism Treatment? Health, 6, 1345-1351. http://dx.doi.org/10.4236/health.2014.612165

\section{Submit or recommend next manuscript to SCIRP and we will provide best service} for you:

Accepting pre-submission inquiries through Email, Facebook, LinkedIn, Twitter, etc. A wide selection of journals (inclusive of 9 subjects, more than 200 journals)

Providing 24-hour high-quality service

User-friendly online submission system

Fair and swift peer-review system

Efficient typesetting and proofreading procedure

Display of the result of downloads and visits, as well as the number of cited articles

Maximum dissemination of your research work

Submit your manuscript at: http://papersubmission.scirp.org/

Or contact health@scirp.org 